\title{
Microcontroller Based Security System with Intruder Position
}

\author{
Diarah Reuben Samuel, Ojongbede,H.A \\ ${ }^{I}$ (Electrical and Information Engineering, College of Science and Engineering/Landmark University Omu-Aran, Nigeria) \\ ${ }^{2}$ (Electrical and Information Engineering, College of Science and Engineering/Landmark University Omu-Aran, Nigeria)
}

\begin{abstract}
The microcontroller Based Security System with Intruder Position Display is a design that applies automated security system in homes, Industries, military etc. The project will feature a system that will track the presence of an intruder in restricted area and also inform the user about the position of the intruder.

This Project will be based on microcontroller and other electronic design to achieve the above stated purposes. The interfacing medium will make use of parallel port. The sensors (Light Dependent Resistor and LEDS) will receive the signal when the intruder is around while the control program will translate the received signal from the sensors to useful information about the function of the system.

In this design we have implored the use of both hardware and software to bring about the entire project. The hardware components are solely coordinated by the AT89S51 microcontroller chip while the C programming language is used to program the chip
\end{abstract}

Keywords: Hardware, Microcontroller, programmer, programming and Software.

\section{INTRODUCTION}

The need to secure our home, industries and other related properties has been a subject of interest since the days of our fore fathers, Since then, an aggressive development in the area of security has exponentially been driven to today's trend.

A system cannot have high assurance if it has poor security and requirements. For high assurance, systems will logically include security requirement as well as availability, reliability and robustness requirements [2].

The early-men, in their effort to provide security to their house-hold and properties, used crude measures such as stones, grasses and crude weapons to secure themselves. As the intrusion techniques by intruders outgrows the then security measures and more values added to lives and properties, ore sophisticated measures were developed to ensure an intruder proof environment, which today, has become one of the most interesting aspect of individual, National and even international concern. There are three simple do-it-yourself steps you can take to create a home intruder system before you even add any special technological components. (1) Install exterior lights and include either a timer or a motion detector (2) Secure all exterior doors and windows with well-built, sturdy locks (3) Trim back trees and shrubs in your yard, especially around windows and doors, Some home intruder system tasks are easy and fast projects, yet they offer you and your family paramount security.

There are different kinds of home intruder systems, but these are the basic types of components: Wireless Security Alarms: A wireless security alarm offers you good coverage. It is a home intruder system that will stop intruders before they get in and can summon help immediately; making sure your family is absolutely safe.

Micro computer based security system: This system senses the presence of an intruder and alerts the user on the obstruction detected, it also displays the position of the intruder on a screen.

Motion Sensor Lights: Motion sensor lights make intruders react like a deer in the headlights. It is difficult to break into a home when there is a spotlight shining down right on you.

Access Control Gates: Make it hard for the intruder to even get on your property, let alone into your house, by surrounding your home with a high fence and installing an access control gate. An access control gate gives you specific points of entry onto your property, and you can monitor them yourself from inside. A gate allows you and friends to come and go, but says "NO!" to intruders. It's a home intruder system that keeps criminals further away from your family.

1.1 The Objective/main benefit of this work is to keep criminals and unwanted guest away from our environments, Common sense dictates us to lock our doors at night and when we are away from home, but residential crime prevention comes in many other shapes and sizes. Effective residential crime prevention depends on everything from properly fitted doors to stopping your mail delivery when away on vacation.

The Basics: Residential crime prevention starts with taking the proper steps to secure the outside of your home. Basic residential crime prevention measures include: Installing outside floodlights, Keeping your yard clutter free, Pruning shrubbery so it doesn't hide windows and doors and Cutting tree limbs back from upper-level windows. 
Not every intrusion can be prevented. Knowing what to do when faced with different situations not only protects your possessions but can save your life.

Doors and Locks: Burglars, on average, spend no more than 60 seconds trying to gain access to a home. Installing proper doors and locks on your home makes breaking in more difficult and often deters burglars.

The following guidelines for doors and locks significantly improve residential crime prevention. Install solid wood or metal doors, Fit each exterior door with properly fitted dead bolts, Do not rely on knob locks or door chains; they are easily broken, Secure sliding glass doors with commercial grade locks or place a sturdy dowel in the door track and Never hide keys around the outside of your home; instead give a spare to a trustworthy neighbor.

Alarm Systems: An alarm system installed in your home, especially if you live in a secluded area or high-crime neighborhood, can provide needed residential crime prevention. To achieve effective residential crime prevention, you first need to evaluate your home's needs. Your home's location and surroundings determine the level of residential crime prevention you need.

\subsection{The Justification Of The work}

Environmental security against an intruder has become a thing of individual, national and international concern. The essence of this project is to provide a cost effective and more efficient security system in areas like homes, industries military etc.The application of this project will enhance effectiveness necessitating to security measures. It relevance, upgrades the conventional security system to automated system that will require little of human intervention.

This project will also build a platform for further sophistication of automated security system by detailing all the measures taken in realizing this system.(microcomputer Based Security System). This will ensure a complete intruder proof system which will take care of future intrusion technique.

\subsection{Scope of Project}

Since security systems ranges from simple to complex systems, in trends and effectiveness. The depth of mywork on this project will build a system that will be able to check the security of home and small industries. It will feature four (4) sensing circuits that could be check the intrusion of an intruder in up to four different positions or location. A single alarm system that will alert about the presence of an intruder and also, the display of an intruder position using the Visual Display Unit of the microcomputer.

\section{ORIGIN:}

The design of this project (Microcontroller Based Security system with intruder Position Display) was initiated as a result of intrusion of an unauthorized persons into a restricted areas in our homes, Industries, etc. Efforts were made to track down an intruder at a particular time as he try to get to his target.

Due to the pressing need on tracking an intruder at any point in time, I decided to come up with this project work.

\subsection{History of Security}

The need to secure our home, industries and other related properties has been a subject of interest since the days of our fore fathers, Since then, an aggressive development in the area of security has exponentially been driven to today's trend.

The early-men, in their effort to provide security to their house-hold and properties, used crude measures such as stones, grasses and crude weapons to secure themselves. As the intrusion techniques by intruders outgrows the then security measures and more values added to lives and properties, ore sophisticated measures were developed to ensure an intruder proof environment, which today, has become one of the most interesting aspect of individual, National and even international concern.

\subsection{Home Intruder System Basics}

There are three simple do-it-yourself steps you can take to create a home intruder system before you even add any special technological components. (1) Install exterior lights and include either a timer or a motion detector (2) Secure all exterior doors and windows with well-built, sturdy locks (3) Trim back trees and shrubs in your yard, especially around windows and doors, Some home intruder system tasks are easy and fast projects, yet they offer you and your family paramount security.

There are different kinds of home intruder systems, but these are the basic types of components: Wireless Security Alarms: A wireless security alarm offers you good coverage. It is a home intruder system that will stop intruders before they get in and can summon help immediately; making sure your family is absolutely safe. 
Micro computer based security system: This system senses the presence of an intruder and alerts the user on the obstruction detected, it also displays the position of the intruder on a screen.

Motion Sensor Lights: Motion sensor lights make intruders react like a deer in the headlights. It is difficult to break into a home when there is a spotlight shining down right on you.

Access Control Gates: Make it hard for the intruder to even get on your property, let alone into your house, by surrounding your home with a high fence and installing an access control gate. An access control gate gives you specific points of entry onto your property, and you can monitor them yourself from inside. A gate allows you and friends to come and go, but says "NO!" to intruders. It's a home intruder system that keeps criminals further away from your family.

\subsection{Residential crime Prevention}

Common sense dictates us to lock our doors at night and when we are away from home, but residential crime prevention comes in many other shapes and sizes. Effective residential crime prevention depends on everything from properly fitted doors to stopping your mail delivery when away on vacation.

The Basics: Residential crime prevention starts with taking the proper steps to secure the outside of your home. Basic residential crime prevention measures include: Installing outside floodlights, Keeping your yard clutter free, Pruning shrubbery so it doesn't hide windows and doors and Cutting tree limbs back from upper-level windows.

Not every intrusion can be prevented. Knowing what to do when faced with different situations not only protects your possessions but can save your life.

Doors and Locks: Burglars, on average, spend no more than 60 seconds trying to gain access to a home. Installing proper doors and locks on your home makes breaking in more difficult and often deters burglars.

The following guidelines for doors and locks significantly improve residential crime prevention. Install solid wood or metal doors, Fit each exterior door with properly fitted dead bolts, Do not rely on knob locks or door chains; they are easily broken, Secure sliding glass doors with commercial grade locks or place a sturdy dowel in the door track and Never hide keys around the outside of your home; instead give a spare to a trustworthy neighbor.

Alarm Systems: An alarm system installed in your home, especially if you live in a secluded area or high-crime neighborhood, can provide needed residential crime prevention. To achieve effective residential crime prevention, you first need to evaluate your home's needs. Your home's location and surroundings determine the level of residential crime prevention you need.

\section{Design Process:}

A micro-controller based project design process is characterized by the following;

* Definition of task

* Requirements

* Factor that influence choice

In defining a task, every design comes from an idea or a problem that requires a solution. Questions may be generated on what exactly that is required to be achieved and the feasibility of the ideas as regards to the implementation.

If these questions are analyzed critically with tangible solutions to the problem, a development of this idea into a reality is the next step.

Requirements for design process have to be considered once an idea has been established. The need to determine whether or not the idea requires a PC or not, depending on the complexity of the circuitry, or whether the circuits to be designed needs to make a complex decision or deal with complex data.The compare these factors with topic with IC's (AND gates) which two inputs when high logic changes outputs. Preferably, a micro-controller will be the best option based on the circuits to be designed with less hardware connections and flexibility.

Writing a program that performs a desired function accesses the ability of the micro-controller. However, it came to our thought that among all the components used here the one that consumes the highest power is the Light Emitting Diodes (LEDs), which need as much as 15-volt to glow and draw as maximum as 2-ampere of current. As a result if this, we decided to use 15-volts, 2-ampere rated transformer for this design. After the voltage is stepped down 15 -volts using a transformer, a full wave rectifier circuit was designed using four Diodes (IN4001). This value of Diodes is used here because from the specification of voltage/Diode rectifying data book, this value is adequate for lower voltages, say 0-24 volt. The load current of the rectifier is given as follows;

$\mathrm{Idc}=21 \mathrm{~m} / 3.1$

When $1 \mathrm{~m}=$ maximum current $=2 \mathrm{amp}$ 
Idc $=$ load current which is in dc form after recification.

Hence idc $=2 * 3 / 3.14=4 / 3.14$, idc $=1.27$ amps

Therefore $1.27 \mathrm{amps}$ is the maximum load current that can be drawn in the whole system. Also it is known that after rectification, the same voltage (15-volts) continues to flow into the filter. As a result the load voltages 15 -volts

Thus Vdc $=$ Load voltage $=15$ volts

And $\mathrm{Vdc}=21 \mathrm{~m} * \mathrm{RL} / 3.14$

$\mathrm{RL}=$ Load resistance,$\quad \mathrm{RL}=47.13 / 4$

$\mathrm{RL}=11.78 * 3.14=1.78$

From this, it is obvious that $\mathrm{V}=\mathrm{IR}=1.27 * 1.27$

\subsection{Power supply unit}

There are many types of power supply. Most are designed to convert high voltage AC mains electricity to a suitable low voltage supply for electronics circuits and other devices. A power supply can by broken down into a series of blocks, each of which performs a particular function.

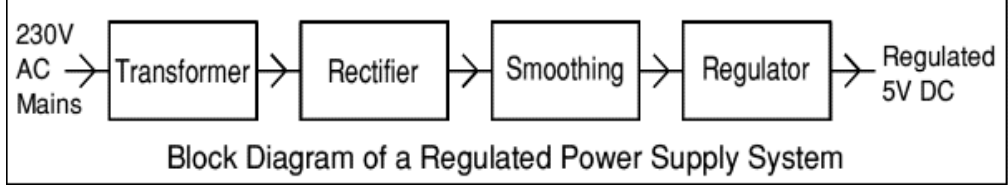

Figure 3.1.1: A 5V regulated supply

- Transformer: steps down high voltage AC mains to low voltage AC.

- Rectifier: converts AC to DC, but the DC output is varying.

- Smoothing: smoothes the DC from varying greatly to a small ripple.

- Regulator: eliminates ripple by setting DC output to a fixed voltage.

Power supplies made from these blocks are described below with a circuit diagram and a graph of their output:

- Transformer only

- Transformer + Rectifier

- $\quad$ Transformer + Rectifier + Smoothing

- Transformer + Rectifier + Smoothing + Regulator

Transformer Only:
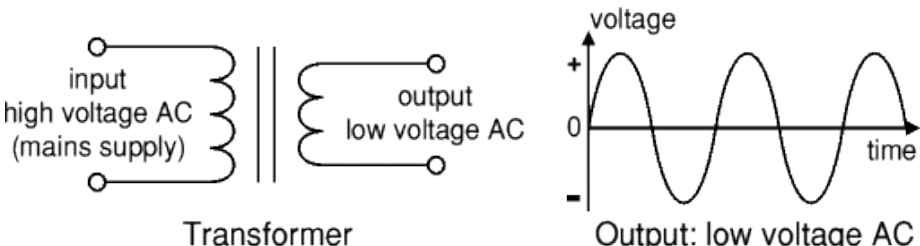

Output: low voltage AC

Figure 3.1:

fig 3.1.Transformer circuit and waveform representation

The low voltage AC output is suitable for lamps, heaters and special AC motors. It is not suitable for electronic circuits unless they include a rectifier and a smoothing capacitor.

\section{Transformer + Rectifier}

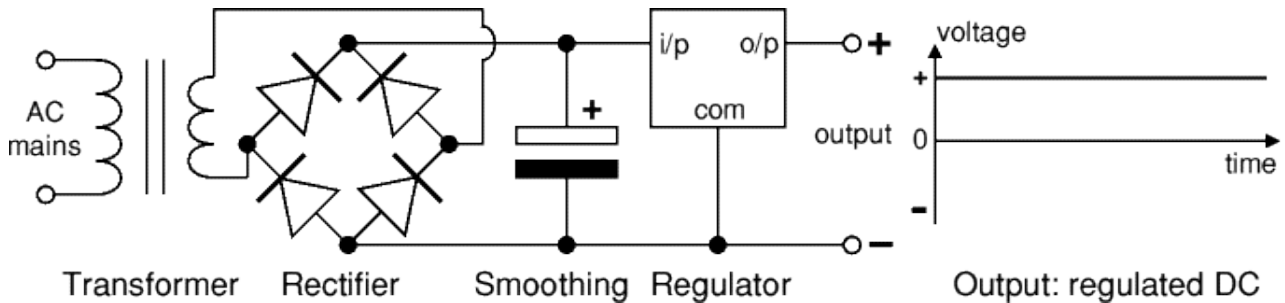

Figure3.1.2: Transformers + Rectifier + Capacitor + Regulator

\subsection{DISPLAY UNIT:}

the display unit consists of $16 * 2$ liquid crstal display that dispays the position of the intruder as well as the condition of the alarm system. The lower data bus of the LCD is connected to port 2 of the microcontroller while RS and EN pins are connected to port 3_0 and port 3_1 respectively. 


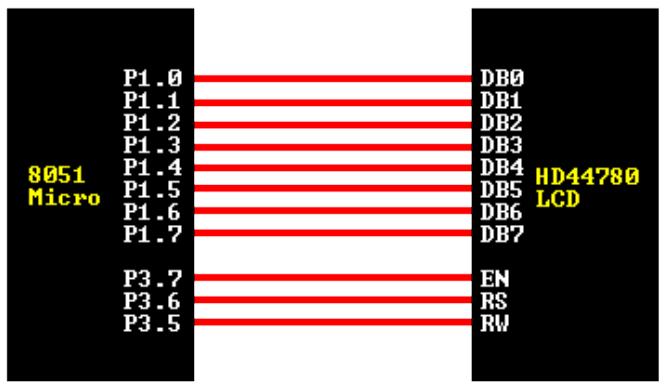

Fig 3.2.1 Connection between Microcontroller and LCD

\subsection{The Input Interface Design}

The input interface is a circuitry that enables the system to fetch signal (visitor presence) from the moni $\cdots$ on. Its design is ach $\cdots$ : of Light Dependent Resistors (LDR), Light emitting Diod Vin sistors and Transisto Vcc ng Voltage Divider principle. As shown in the figure

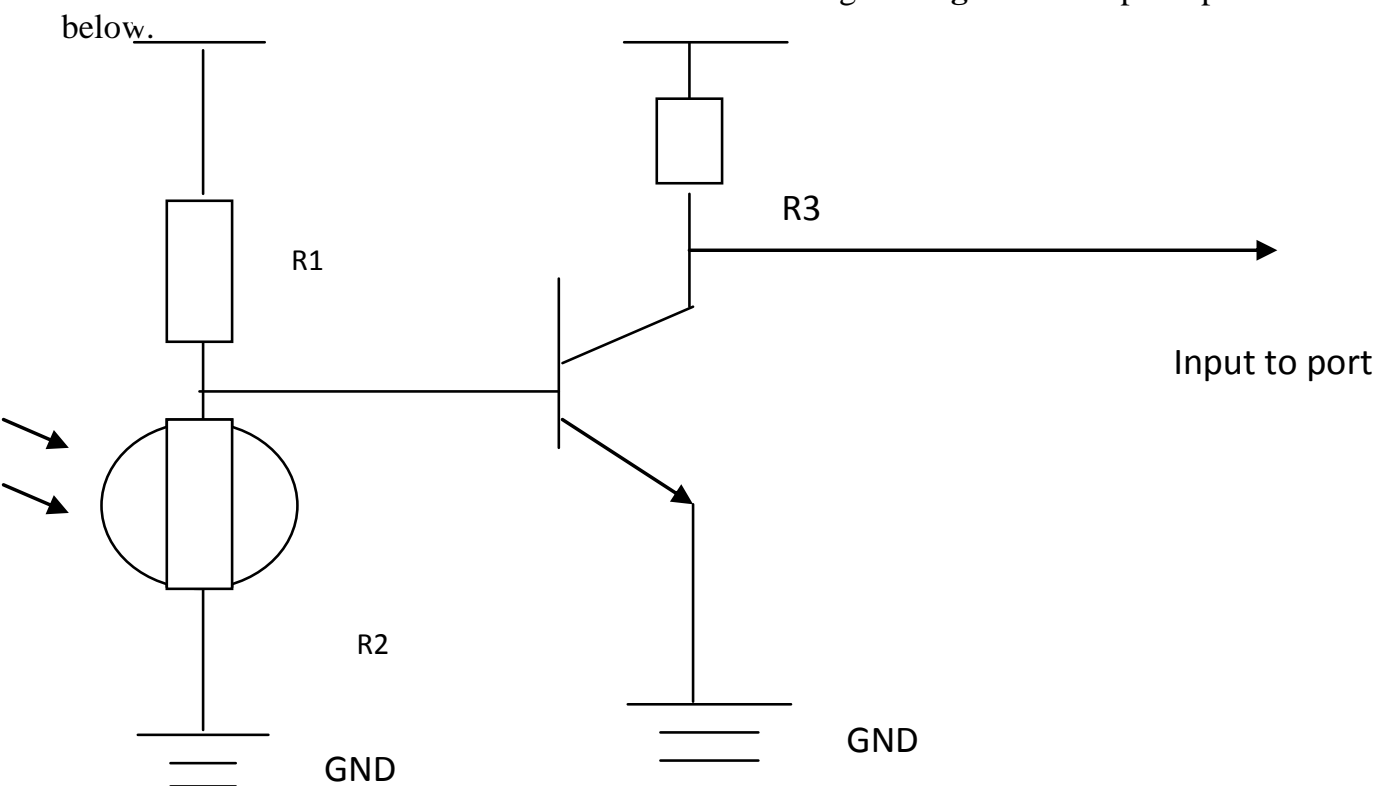

Figure 3.3.1: Input Sensor Design

Most input transducers (sensors vary their resistance and usually voltage divider is used to convert this to a varying voltage which is more useful. The voltage signal in this context is fed as an input into a NPN (C945) transistor switch.

Choosing the resistor value

The value of the resistance $\mathrm{R}$ will determine the range of the output voltage. Using a multimeter to find the minimum and the maximum values of the sensor's (LDR) resistance(Rmin*Rmax).

In this context: $\mathrm{Rmin}=1.50 \mathrm{~K} \Omega$

$$
\mathrm{Rmax}=780 \mathrm{k} \Omega
$$

$\mathbf{R}=$ square root of $(\mathbf{R} \min * \mathbf{R} \max )=$ Square root of $(1.50 \mathrm{k} \Omega * 780 \mathrm{k} \Omega)$

Since the system is capable of monitoring four different positions, the above design was repeated four times to serve as input to the parallel port status pins.

\section{The transistor input}

Vout $=($ Vin $\times \mathrm{R} 2) /(\mathrm{R} 1+\mathrm{R} 2)$

Vin $=5 \mathrm{v}$, Thus, in darkness

Vout $=5 \times 780 \times 10^{3} / 4.7 \times 10^{3}+780 \times 10^{3}$

Vout $=39 \times 10^{5} / 784700$

Vout $=4.97 \mathrm{v}$

This increases the base current that drives the transistor to saturation.

In bright light:

Vout $=5 \times 9.5 / 4.7 \times 10^{3}+9.5$

Vout $=47.5 / 4709.5$, Vout $=0.01 \mathrm{v}$ 
Where Vout $=\mathrm{V}_{\mathrm{BE}}$.

\section{Analysis}

Since LDR has large resistance when dark and a low resistance when brightly lit, thus if R2 is much larger than R1, Vout is large because most of the voltage are across R2

Thus when intruder's shadow is cast on the LDR , there is increase in the LDR's resistance bringing about increase base current $\mathrm{I}_{\mathrm{b}}$ enough to drive the NPN transistor to saturation, this causes the collector current to flow into the parallel port input.

$\mathrm{Ic}=\mathrm{Vcc} / \mathrm{Rc}$

\subsection{Microcontroller unit:}

The AT89C51 is a low power, high performance cmos 8-bit microcomputer with 4Kbytes of flash programmable and erasable read only memory (PEROM). The device is manufactured using Atmel`s high density nonvolatile memory technology and is compatible with the industry standard MCS-51 instruction set and pinout. The on-chip flash allows the program memory to be reprogrammed in system or by a conventional nonvolatile memory programmer. By combining a versatile 8-bit CPU with flash on a monolithic chip, the Atmel AT89C51 is a powerful microcomputer, which provides a highly flexible and cost effective solution to many embedded control application.

The AT89C51 is designed with static logic for operation down to zero frequency and support two software selectable power saving modes. The idle mode stops the CPU while allowing the RAM, timer/counters, serial port and interrupt system to continue functioning. The power down mode saves the RAM contents but freezes the oscillator disabling all other chip functions until the next hardware reset.

\section{System Block Diagram}

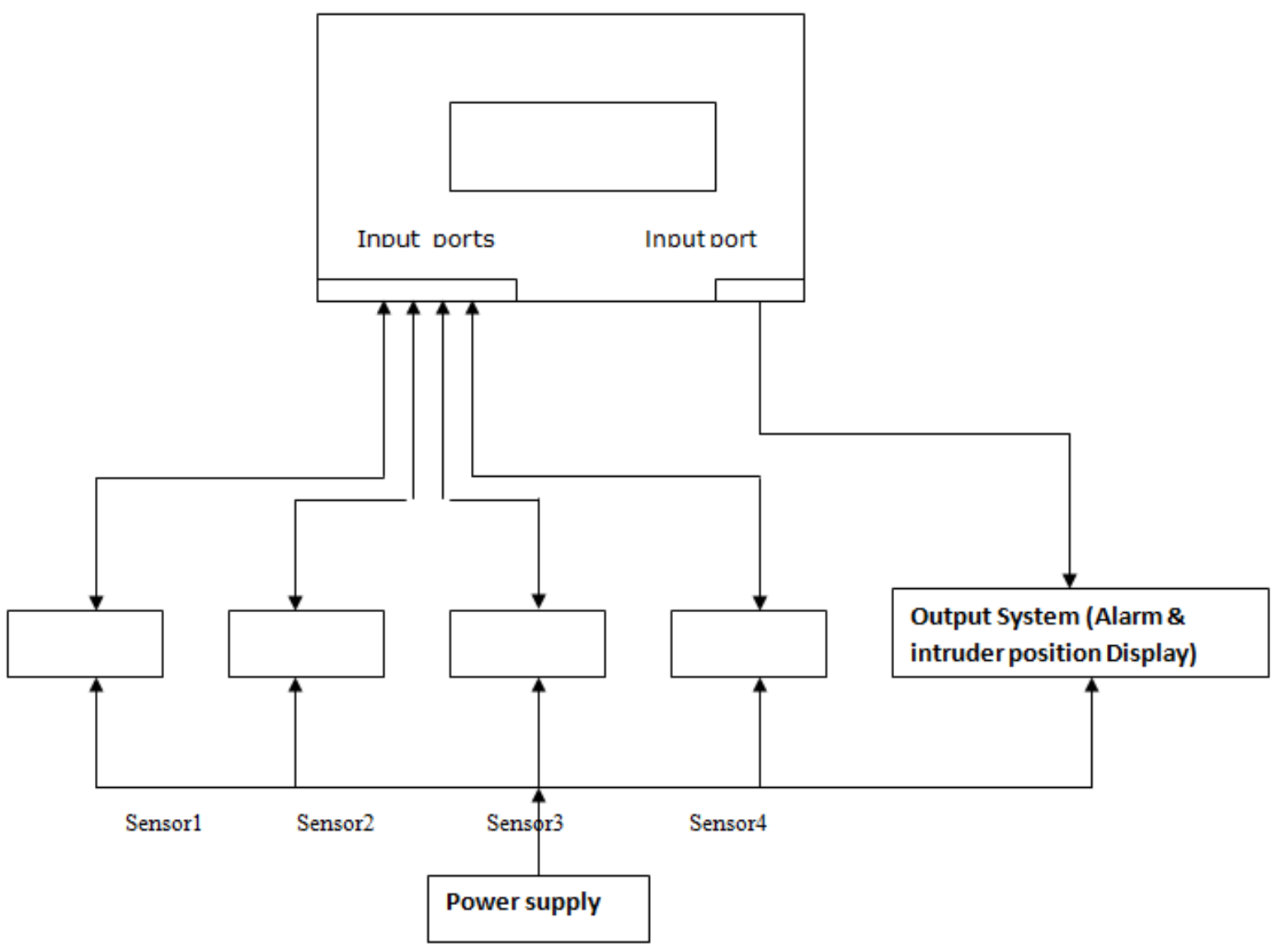

Figure 4.0 : system Block Diagram 


\subsection{Program Flowchart}

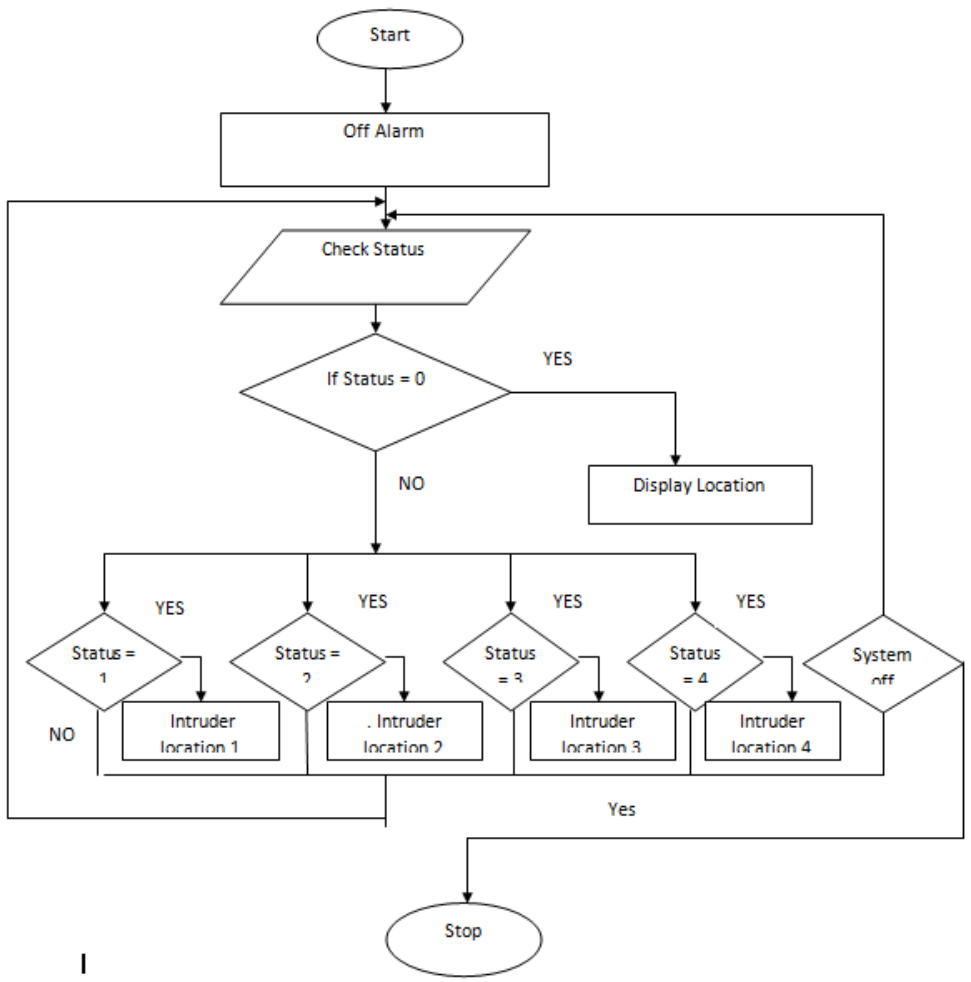

Figure 4.1.1: Program Flowchart

\subsection{CIRCUIT DIAGRAM OF PROJECT}

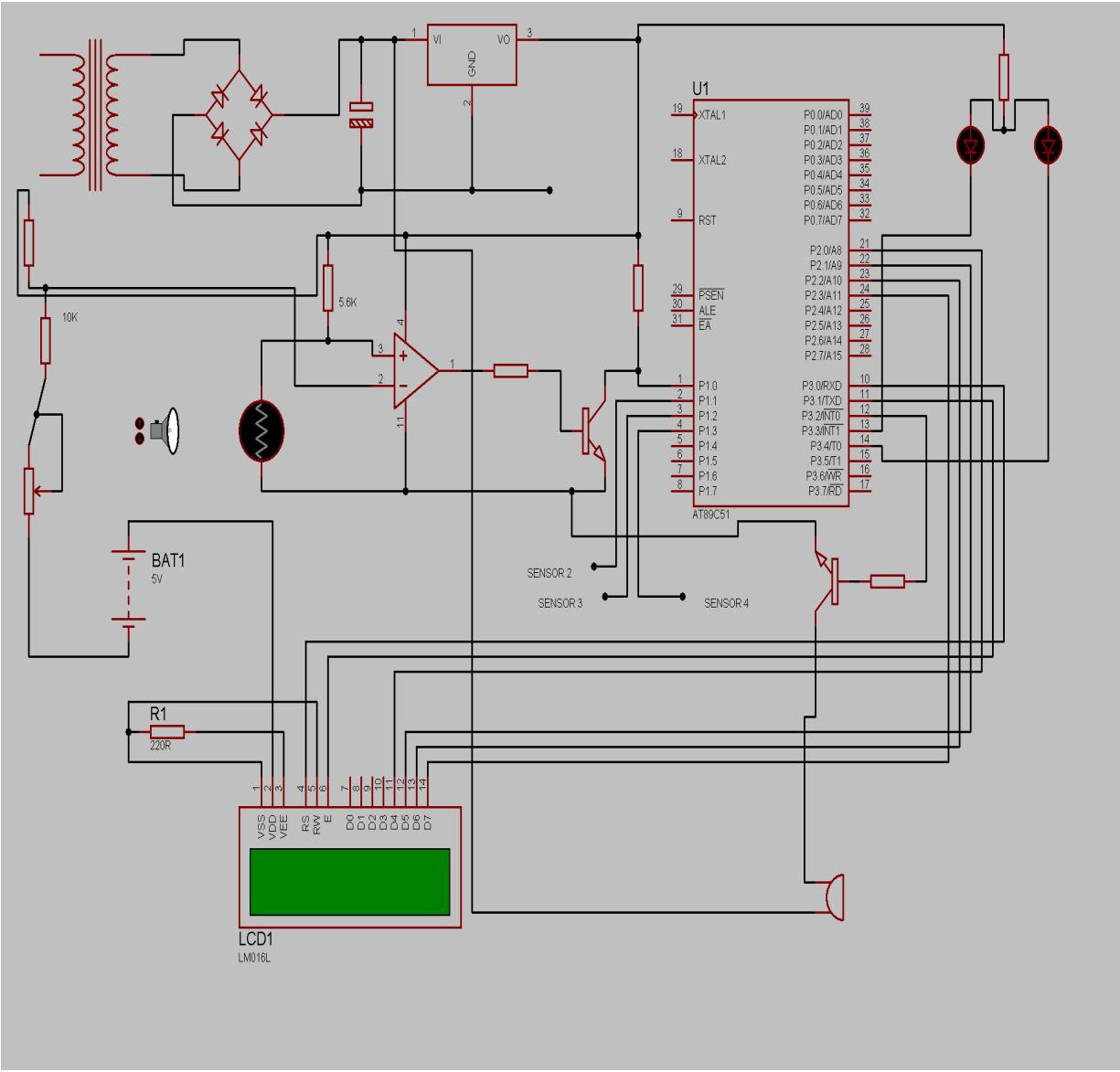

Fig 4.2.1 circuit diagram 
Table 4.3 Experimented Value/ Actual value

\begin{tabular}{|c|c|c|c|c|}
\hline COMPONENTS & $\begin{array}{l}\text { EXPERIMENTED } \\
\text { VALUE }\end{array}$ & $\begin{array}{l}\text { ACTUAL } \\
\text { VALUE }\end{array}$ & UNIT & TOLERANCE \\
\hline Resistor & $\begin{array}{l}10000 \\
2000 \\
220 \\
10000\end{array}$ & $\begin{array}{l}10000 \\
2000 \\
218 \\
9980\end{array}$ & $\begin{array}{l}\Omega \\
\Omega \\
\Omega \\
\Omega\end{array}$ & $5 \%$ \\
\hline Capacitor & $\begin{array}{l}10 \\
10 \\
30\end{array}$ & $\begin{array}{l}10.20 \\
10.15 \\
29.82\end{array}$ & $\begin{array}{l}\mu f \\
\rho f \\
\rho f\end{array}$ & \\
\hline Transistor & $\begin{array}{ll}\mathrm{R}_{\mathrm{be}} & 520 \\
\mathrm{R}_{\mathrm{bc}} & 510\end{array}$ & $\begin{array}{l}550 \\
548\end{array}$ & $\begin{array}{l}\Omega \\
\Omega\end{array}$ & \\
\hline Transformer voltage & 12Vac@ 240Vac input & $\begin{array}{l}13.2 @ \\
210\end{array}$ & $\begin{array}{l}\mathrm{V} \\
\mathrm{V}\end{array}$ & \\
\hline Regulator & 5.00 & 5.02 & $\mathrm{~V}$ & \\
\hline
\end{tabular}

\section{Conclusion}

In this paper we have implored the use of both hardware and software to bring about the entire project. The hardware components are solely coordinated by the AT89S51 micro controller

Going through the planning, flow process, design and software implementation the system had really been tough one; but on the whole it has been a chance to show case a little bit of craftsmanship. There are multiple numbers of security systems are available to protect our computer/resources. Among them, password based systems are the most commonly used system due to its simplicity, applicability and cost effectiveness [1]

\section{References}

[1]. Mitra Thakur, Enhanced Password Based Security System Based on User Behavior using Neural Networks, I.J. Information Engineering and Electronic Business, 2012, 2, 29-35, Published Online April 2012 in MECS (http://www.mecspress.org/),DOI: 10.5815/ijieeb.2012.02.05.

[2]. Ramesh bharadwaj, DEVELOPMENT OF HIGH-ASSURANCE DISTRIBUTED SYSTEMS, .,2nd international workshop on requirements engineering for high assurance systems(rhas'03), september9, 2003.monterery bay, California,usa.in conjection with the 11th IEEE international requirements engineering conference.

[3]. Belone Schilling, Electronic Circuits: Discrete and Integrated, McGraw-Hill, New York,1979.

[4]. B.L Theraja and A.K Theraja, A Textbook on Electrical Technology, 2003, 23 ${ }^{\text {rd }}$ Edition, Pp $1887-$ Pp 1888.

[5]. Paul Horowitz and Windfield Hill, The Art of Electronics, 1989, 2 2d Edition, Pp 7- Pp 8, Pp 55 - Pp 58, Pp 614 - Pp 622.

[6]. Atmel Corporation Data Sheet on AT89C51, 0285D-B-12/97

[7]. NTE Electronics Inc., ECG Data Book, January 2002, $10^{\text {th }}$ Edition.

[8]. Giorgio Rizzoni, Principles of Electrical Engineering, 2003, $3^{\text {rd }}$ Edition,

[9]. Ronald .J Tocci, Digital Systems, Arentice - Hall. Inc. USA, 1988.

[10]. Mark Burgess, C programming tutorial, (K \& R version 4). 